Original Research Paper

\title{
Clinical Analysis of Pulmonary Nocardiosis in a Tertiary Hospital
}

\author{
Yoshihiro Kobashi, Makoto Kittaka, Ryo Shirai, Shigeki Kato and Mikio Oka
}

Division of Respiratory Medicine, Kawasaki Medical School, Japan

\author{
Article history \\ Received: 11-12-2017 \\ Revised: 20-03-2018 \\ Accepted: 31-03-2018 \\ Corresponding Author: \\ Yoshihiro Kobashi \\ Division of Respiratory \\ Medicine, Kawasaki Medical \\ School, Japan \\ Tel: +81-86-462-1111 \\ Fax: +81-86-464-1041 \\ E-mail: yoshihiro@med.kawasaki- \\ m.ac.jp
}

\begin{abstract}
This study aimed to clarify the clinical characteristics of pulmonary nocardiosis in our tertiary hospital. The subjects consisted of five cases with pulmonary nocardiosis who received a definite diagnosis in our hospital from January 2006 to December 2016. The five patients with pulmonary nocardiosis included four females and one male with a mean age of 65.6 years old. All patients had underlying diseases. The detection methods were respiratory symptoms in four patients and an abnormal chest shadow in one. There were no characteristic laboratory findings. Regarding the radiological findings, an infiltration shadow was the most common finding in this study. In addition, a mass shadow that required differentiation from lung cancer was recognized in one patient. The diagnosis was reached using bronchoscopic specimens in all patients. The causative microorganisims consisted of Nocardia farcinica in three, Nocardia puris in one and Nocardia elegans in one. The drug susceptibility Totrimethoprim/Sulfamethoxazole (TMP/SMZ) was sensitive in four of five patients. Although TMP/SMZ was administered to all patients as treatment, two patients required a change of antimicrobial agents because of adverse drug events. However, the clinical effect was good for all patients because of early treatment initiation. The conclusions of this study areas follows: (1) pulmonary nocardiosis occursin immunocompetent patients with underlying respiratory diseases and patients undergoing immunosuppressive treatments; (2) there are no characteristic findings of pulmonary nocardiosis in the laboratory or radiological findings; (3) local respiratory clinical specimens using bronchoscopy were useful to obtain a definite diagnosis; (4) no patients had contracted TMP/SMZ-resistant Nocardia species and the clinical effect and prognosis were good.
\end{abstract}

Keywords: Pulmonary Nocardiosis, TMP/SMZ, Bronchoscopy

\section{Introduction}

Nocardia is a genus of aerobic Gram positive bacilli that mainly effects immunocompromised patients such as those receiving immunosuppressive drugs for a long time, Acquired Immunodeficiency Syndrome (AIDS) patients and recipients of organ transplantations (Ambrosioni et al., 2010). It causes infectious diseases including skin and pulmonary infections and disseminated diseases. Pulmonary nocardiosis is a rare infectious disease, but clinical findings in several recent reports have been noted (Kurihara et al., 2014; Chen et al.,
2013; Garcia-Bellmunt et al., 2012; Martinez Tomas et al., 2007). If pulmonary nocardiosis is not diagnosed early enough to initiate the appropriate treatment, it results in high morbidity and poor prognosis (Brown-Elliott et al., 2006; Lerner, 1996). However, an early diagnosis of pulmonary nocardiosis may be difficult because clinical signs or symptoms are nonspecific. Therefore, clinical suspicion of pulmonary nocardiosis is necessary. Because the taxonomy of Nocardia species has been changing, it is difficult to decide on a routine identification and molecular characterization (PCRRFLP) of Nocardia isolates (Valenzuela-Tovar et al., 
2005). The taxonomy of Nocardia species has recently evolved and molecular methods such as 16s rRNA gene sequence analysis have led to a more appropriate classification (Wilson, 2012; Liu et al., 2011).

The aim of this study was to investigate the clinical characteristics, microbiological findings (using molecular analysis as far as possible), treatment and prognosis for patients with pulmonary nocardiosis at a tertiary hospital in Japan.

\section{Patients and Methods}

We selected patients diagnosed as pulmonary nocardiosis in Kawasaki Medical School Hospital, Kurashiki, Japan with a total capacity of 1182 beds, based on a retrospective review from January 2006 to December 2016. In this study, patients with no abnormal shadows in the lung radiologically despite the isolation of Nocardia species were excluded as airway Nocardia colonization. Pulmonary nocardiosis was defined as the presence of abnormal shadows radiologically, with Nocardia species isolated from respiratory clinical sample cultures at least once. This study protocol was approved by the Ethical Committee of Kawasaki Medical School.

Regarding the radiological findings, several pulmonary physicians and radiologists in our hospital retrospectively reviewed the Computed Tomography (CT). The reviewers classified cases using the following findings; airspace consolidation, nodules, cavity, ground glass opacity, pleural effusion and mass lesion.

Concerning microbiological identification, clinical specimens were smeared using Gram-staining to detect the presence of Grampositive filamentous organisms, acid-fast stained using a modified method and incubated on agar plates. The identification of Nocardia species was performed using conventional biochemical tests for Nocardia (Saubolle and Sussland, 2003). Antimicrobial susceptibility testing was done using the disk diffusion method with several antibiotics including Trimethoprim/Sulfamethoxazole (TMP/SMZ) on Muller-
Hinton agar according to the National Committee for Clinical Laboratory Standards criteria (NCCLS, 2003). The identification of Nocardia species was confirmed by 16s ribosome RNA gene sequence analysis.

The following clinical data were collected from the medical records: Patient demographics, underlying diseases, clinical symptoms, laboratory findings, radiological findings, diagnostic methods, bacteriological findings including antimicrobial susceptibility, treatments and prognosis.

\section{Results}

There were five patients with pulmonary nocardiosis in our tertiary hospital during the period of this study. The average age was 65.6 years old and there was one male and four females. One patient had a smoking history and all patients had underlying diseases. Three patients had underlying respiratory diseases such as bronchiectasis or Chronic Obstructive Lung Disease (COPD) and two patients had received immunosuppressive treatment. The chief complaints were respiratory symptoms such as cough or sputum in four patients and a chest abnormal shadow in one (Table 1).

The main laboratory findings of patients with pulmonary nocardiosis were a mild or moderate inflammatory response in all patients and hypoalbuminemia in four of five patients. Although QuantiFERON TB-Gold In-Tube (QFT-IT) showed a positive response in Case 1 and Aspergillus antigen showed a positive response in Case 4, Mycobacterium and Fungus species were not detected from the respiratory specimens from the lesions using bronchoscopy. There were no characteristic findings in the diagnosis of pulmonary nocardiosis (Table 1).

The radiographic findings using chest $\mathrm{CT}$ are shown in Table 2. The predominant findings were airspace consolidation (Fig. 1), but small nodules or a cavity were recognized in one patient. Only a mass shadow $(30 \times 35$ $\mathrm{mm}$ ) was present in the hilum of the right lower lobe and this required differentiation from primary lung cancer because of vascular indentation (Fig. 2).

Table 1: Clinical findings of pulmonary nocardiosis experienced in our hospital (1)

\begin{tabular}{|c|c|c|c|c|c|c|c|c|c|c|c|}
\hline \multirow[b]{2}{*}{ Case } & \multirow[b]{2}{*}{$\begin{array}{l}\text { Age, } \\
\text { Sex }\end{array}$} & \multirow{2}{*}{$\begin{array}{l}\text { Smoking history } \\
\text { (Cigarette/day } \\
\text { x years) }\end{array}$} & \multirow[b]{2}{*}{$\begin{array}{l}\text { Underlying } \\
\text { disease }\end{array}$} & \multirow[b]{2}{*}{$\begin{array}{l}\text { Chief } \\
\text { complaints }\end{array}$} & \multicolumn{7}{|c|}{ Laboratory findings } \\
\hline & & & & & $\begin{array}{l}\text { WBC } \\
(/ \mu \ell)\end{array}$ & $\begin{array}{l}\text { CRP } \\
(\mathrm{mg} / \mathrm{d} \ell)\end{array}$ & $\begin{array}{l}\mathrm{Tb} \\
(\mathrm{g} / \mathrm{d} \ell)\end{array}$ & $\begin{array}{l}\mathrm{Alb} \\
(\mathrm{g} / \mathrm{d} \ell)\end{array}$ & HIV & $\begin{array}{l}\beta \text {-D-glucan } \\
(\mathrm{pg} / \mathrm{ml})\end{array}$ & others \\
\hline 1 & $50, \mathrm{~F}$ & $(-)$ & $\begin{array}{l}\text { Bronchiectasis } \\
\text { Pneumonia } \\
\text { Pleuritis }\end{array}$ & $\begin{array}{l}\text { Fever } \\
\text { Cough } \\
\text { Sputum }\end{array}$ & 5020 & 1.45 & 6.7 & 3.6 & $(-)$ & $<6.0$ & $\mathrm{QFT}(+)$ \\
\hline 2 & $67, \mathrm{~F}$ & $(-)$ & Bronchiectasis & Cough & 4850 & 0.75 & 7.5 & 4.5 & $(-)$ & $<6.0$ & $(-)$ \\
\hline 3 & $80, \mathrm{~F}$ & $(-)$ & $\begin{array}{l}\text { Subarachnoid } \\
\text { Hemorrhage } \\
\text { Chronic sinusitis }\end{array}$ & $\begin{array}{l}\text { Cough } \\
\text { Sputum } \\
\text { General fatigue }\end{array}$ & 7660 & 1.31 & 7 & 3.5 & $(-)$ & $<6.0$ & $(-)$ \\
\hline 4 & $74, \mathrm{M}$ & $(+)(10 \times 40)$ & $\begin{array}{l}\text { COPD } \\
\text { AIHA (Steroid) }\end{array}$ & $\begin{array}{l}\text { Cough } \\
\text { Sputum }\end{array}$ & 10790 & 16.16 & 5.6 & 3.2 & $(-)$ & $<6.0$ & $\begin{array}{l}\text { Aspergillus } \\
\text { antigen (+) }\end{array}$ \\
\hline 5 & $57, \mathrm{~F}$ & $(-)$ & SLE (Steroid) & $(-)$ & 5820 & 0.53 & 5.7 & 3.3 & $(-)$ & $<6.0$ & $(-)$ \\
\hline
\end{tabular}

COPD: Chronic Obstructive Pulmonary Disease, AIHA: Autoimmune Hemolytic Anemia SLE: Systemic Lupus Erythematosus, WBC: White Blood Cell, CRP: C-reactive Protein, TP: Total Protein, Alb: Albumin, HIV: Human Immunodeficiency Virus 
Table 2: Clinical findings of pulmonary nocardiosis experienced in our hospital (2)

\begin{tabular}{|c|c|c|c|c|c|c|c|c|c|c|c|c|}
\hline \multirow[b]{2}{*}{ Case } & \multicolumn{6}{|c|}{ Radiological findings } & \multirow[b]{2}{*}{$\begin{array}{l}\text { Diagnostic } \\
\text { method }\end{array}$} & \multirow[b]{2}{*}{$\begin{array}{l}\text { Time to } \\
\text { diagnosis }\end{array}$} & \multirow[b]{2}{*}{$\begin{array}{l}\text { Causative } \\
\text { microorganism }\end{array}$} & \multirow{2}{*}{$\begin{array}{l}\text { Drug } \\
\text { sensitivity test } \\
\text { (Resistant to } \\
\text { TMP/SMZ) } \\
\end{array}$} & \multirow[b]{2}{*}{ Treatment } & \multirow[b]{2}{*}{ Prognosis } \\
\hline & Consolidation & Nodules & Cavity & GGO & $\begin{array}{l}\text { Pleural } \\
\text { effusion }\end{array}$ & Mass & & & & & & \\
\hline 1 & $(+)$ & $(-)$ & $(-)$ & $(-)$ & $(-)$ & $(-)$ & Bronchoscopy & 2 weeks & $\begin{array}{l}\text { Nocardia } \\
\text { farcinica }\end{array}$ & $(-)$ & $\begin{array}{l}\text { TMP/SMZ } \\
\text { (Stopped) } \\
\quad \downarrow \\
\text { LVFX(Poor) } \\
\quad \downarrow \\
\text { AMK IPM/cs } \\
\quad \downarrow \\
\text { TMP/SMZ } \\
\text { (Good) }\end{array}$ & $\begin{array}{l}\text { Survival } \\
\text { (5 years) }\end{array}$ \\
\hline 2 & $(+)$ & $(+)$ & $(-)$ & $(-)$ & $(-)$ & $(-)$ & Bronchoscopy & 2 weeks & $\begin{array}{l}\text { Nocardia } \\
\text { puris }\end{array}$ & $(-)$ & $\begin{array}{l}\text { TMP/SMZ } \\
\text { (Good) }\end{array}$ & $\begin{array}{l}\text { Survival } \\
\text { (6 months) }\end{array}$ \\
\hline 3 & $(+)$ & $(-)$ & $(-)$ & $(+)$ & $(-)$ & $(-)$ & Bronchoscopy & 3 weeks & $\begin{array}{l}\text { Nocardia } \\
\text { farcinica }\end{array}$ & $(-)$ & $\begin{array}{l}\text { TMP/SMZ } \\
\text { (Stopped } \\
\quad \downarrow \\
\text { MINO (Good)) }\end{array}$ & $\begin{array}{l}\text { Survival } \\
\text { (5 years) }\end{array}$ \\
\hline 4 & $(+)$ & $(-)$ & $(+)$ & $(-)$ & $(-)$ & $(-)$ & Bronchoscopy & 2 weeks & $\begin{array}{l}\text { Nocardia } \\
\text { farcinica }\end{array}$ & N.D. & $\begin{array}{l}\text { TMP/SMZ } \\
\text { (Good) }\end{array}$ & $\begin{array}{l}\text { (Death } \\
\text { Other disease } \\
9 \text { years) }\end{array}$ \\
\hline 5 & $(-)$ & $(-)$ & $(-)$ & $(-)$ & $(-)$ & $(+)$ & Bronchoscopy & 6 weeks & $\begin{array}{l}\text { Nocardia } \\
\text { elegans }\end{array}$ & $(-)$ & $\begin{array}{l}\text { TMP/SMZ } \\
\text { (Good) }\end{array}$ & $\begin{array}{l}\text { Survival } \\
\text { (6 months) }\end{array}$ \\
\hline
\end{tabular}
Minocycline
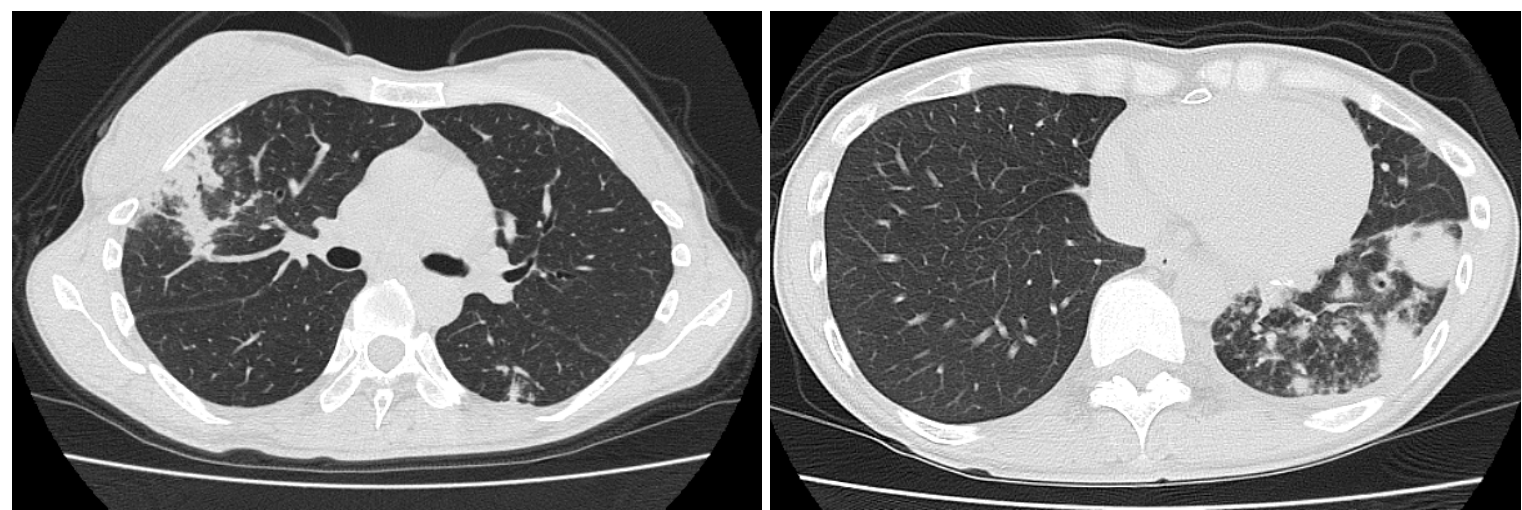

Fig. 1: Chest CT on admission showing an infiltration shadow with bronchiectasis in the right upper lobe and left lower lobe. (Case 1)

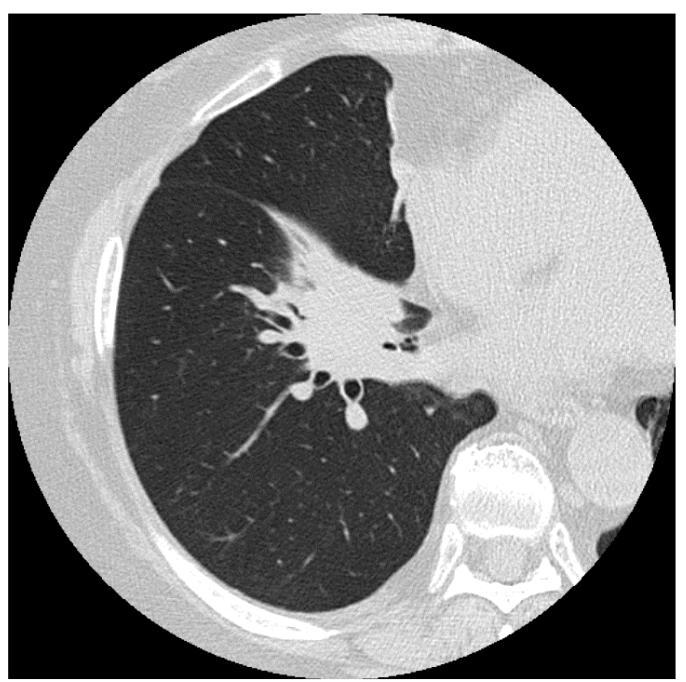

Fig. 2: Chest $\mathrm{CT}$ on admission showing a mass shadow $(30 \times 35$ $\mathrm{mm}$ ) in the right hilum (headarrow). (Case 5)
The diagnostic methods consisted of culture of local respiratory clinical samples using bronchoscopy in all patients. The time required to obtain a definite diagnosis was from two to six weeks. Regarding the microbiological identification of Nocardia species using 16s rRNA gene sequence analysis, $N$. farcinica was most frequently found in three patients, $N$. puris in one and $N$. elegans in one, respectively. Other causative microorganisms such as Mycobacterium, fungus species or common bacteria were not detected respiratory specimens from the lesions using bronchoscopy in any patients. No patients had contracted TMP/SMZ-resistant Nocardia species in this study. The treatment for pulmonary nocardiosis consisted of TMP/SMZ antibiotics in the first protocol. However, two patients required a change of antimicrobial agents (MINO or IPM/CS) because of adverse drug events. Finally, the clinical effect and prognosis were good for all patients. 


\section{Discussion}

We tried to clarify the clinical characteristics of pulmonary nocardiosis experienced in our tertiary hospitalin this study. In previous reports, pulmonary nocardiosis tended to affect patients in an immunocompromised condition due to corticosteroid drugs or biological drugs (Ambrosioni et al., 2010) and with underlying respiratory diseases such as COPD (Kurihara et al., 2014; Chen et al., 2013; Menendez et al., 1997). In our study, four of five patients with pulmonary nocardiosis received immunosuppressive drugs and had underlying respiratory diseases, as in previous studies.

Regarding the radiological findings on chest $\mathrm{CT}$, the most common CT findings were airspace consolidation, nodules, pleural effusion and cavity formation (Blackmon et al., 2011; Backley et al., 1995). However, the radiological findings between immunocompetent patients and immunocompromised patients were different: Bronchiectasis and centrilobular nodular opacities in the former and nodules, masses, cavities in the latter (Biscione et al., 2005). Otherwise, there were sometimes mixed infections with Mycobacterium or Aspergillus speciesin patients with pulmonary nocardiosis (Kurihara et al., 2014; Chen et al., 2013). Cavity formation was frequently recognized in these patients (Feigin, 1986). However, although we investigated the clinical specimens from the lesions obtained using bronchoscopy in this study, there were no patients with mixed infection with other microorganisms. Airspace consolidation was the most frequent finding in four cases and nodules, cavities or masses in one, respectively. Because there was no specific radiological pattern for pulmonary nocardiosis, it was difficult to distinguish it from other pulmonary infectious diseases such as pulmonary mycobacterial infection or mycosis in this study.

Nocardia is a Grampositive aerobic bacilli and the taxonomy changes continuously. The final identification requires molecular techniques such as $16 \mathrm{~s}$ rRNA sequencing analysis as in a recent study (Wilson, 2012; Liu et al., 2011). We also identified Nocardia spp. using $16 \mathrm{~s}$ rRNA with the assistance of a special institution in this study (Division of Mycology, National Institute of Infectious Diseases and Medical Mycology Research Center, Chiba University). Subsequently, N. farcinica was most frequently identified in three of five patients and $N$. puris, $N$. elegans in one, respectively. Concerning the identification of Nocardia species using the 16s rRNA technique, while Chen et al. reported that $N$, cyriacigeorgica was most frequently identified in Taiwan and recognized in clinically severe cases (Chen et al., 2013). Hui et al. (2013) reported that $N$. asteroids was most frequently identified in Australia. Considering these previous reports, the difference in identified Nocardiaspecies may depend on the difference in the distribution pattern in the community. Regarding the antimicrobial susceptibility of Nocardia species, although we sent the Nocardia isolates to a special mycology institution and measured the susceptibility for many antibiotics in four of five patients, there was no resistance to TMP/SMZ in any patients. On the other hand, Kuwahara et al. reported that $27 \%$ of Nocardia species were resistant to TMP/SMZ. In particular, both $N$. farcinica and $N$. otitidiscaviarum showed resistance to TMP/SMZ in many patients with pulmonary nocardiosis (Kurihara et al., 2014). Generally, N. farcinica is associated with antibiotic resistance and poor outcomes (Husain et al., 2002; Wallace et al., 1990). However, antimicrobial susceptibility results for this microorganisim have recently varied (Brown-Elliott et al., 2012; Uhde et al., 2010) and it was reported that there are several problems in the inter-laboratory reproducibility of the TMP/SMZ susceptibility test (Conville et al., 2012). Therefore, we consider that it is necessary to reevaluate the relationship between susceptibility tests for antibiotics and clinical effect by linking many laboratory centers around the world.

In the treatment of pulmonary nocardiosis, because the translation rate for the cerebroneurological system of TMP/SMZ has been good, TMP/SMZ have been recommended as the first choice antibiotics for the treatment for Nocardia infection (Sorrell et al., 2005). However, it was reported that TMP/SMZ often caused adverse events and treatment had to be stopped. In this study, TMP/SMZ was administered to all patients, but adverse events appeared in two patients and they had to stop this treatment. When TMP/SMZ cannot be administered due to adverse events, it was reported that amoxicillin/clavulanic acid, MINO, IPM/CS, AMK or CTRX were useful as the second choice antibiotics for the treatment of pulmonary nocardiosis (Menendez et al., 1997; McNeil et al., 1995). Therefore, we selected AMK, IPM/CS and MINO, which showed good sensitivity for the individual patient. Regarding the duration of treatment using TMP/SMZ for pulmonary nocardiosis, Sorrell et al. (2005) reported that at least six months was required for immunocompetent patients with pulmonary or general nocardiasis or immunosuppressed HIV-negative patients. We also think it necessary to administer TMP/SMZ for six months for similar patients and administered to our patients for over six months except for two patients that stopped due to adverse events. However, because there was no evidence about the recommended dose and duration for other antibiotics, a prospective large scale study should be performed for other antibiotics besides TMP/SMZ. 
Concerning the prognosis of Nocardia infection, the mortality rate due to nocardiosis was poor $(80 \%)$ in previous reports (Presant et al., 1973). However, the mortality rate has decreased to $20 \%$ with the appearance of TMP/SMZ (Lederman and Crum, 2004) and the pulmonary nocardiosis survival rates were reported to be 97\% (after 30 days), 83\% (after 90 days) and 74\% (after 180 days) in a recent Japanese report (Kurihara et al., 2014). While the prognosis of pulmonary nocardiosis was good, it was reported that the prognosis was worse when the patient showed a disseminated type or cerebral nocardiosis was complicated, (Yorke, 2003; Menendez et al., 1997; Lerner, 1995). Although there were several patients with pulmonary nocardiosis in our study, no patients died due to the worsening of pulmonary nocardiosis and only one patient died due to another disease during the follow-up period after the remission of pulmonary nocardiosis. As one reason forthe good prognosis, we think that the positive diagnostic method using bronchoscopy was related to the early diagnosis within a few weeks and initiation of treatment in all patients excluding one (Case 6) in this study.

Finally, this study has a few limitations due to its retrospective nature. Firstly, because this study was performed in a single tertiary hospital and excluded patients suspected of airway Nocardia colonization, it was small scale with only five patients with pulmonary nocardiosis. Secondly, although we reported that there were no patients with other infectious diseases except for pulmonary nocardiosis from the culture results of the local specimens from lesions using bronchoscopy, we cannot exclude the possibility of co-infection with other microorganisms completely as the clinical data were collected from the medical previous records based on a retrospective review.

\section{Conclusion}

The conclusions of this study are as follows: (1) pulmonary nocardiosis occurs in immunocompetent patients with underlying respiratory diseases and patients undergoing immunosuppressive treatments; (2) there are no characteristic findings of pulmonary nocardiosis in the laboratory or radiological findings; (3) the local respiratory clinical specimens using bronchoscopy were useful to obtain a definite diagnosis; (4) no patients had contracted TMP/SMZ-resistant Nocardia species and the clinical effect and prognosis were good.

\section{Acknowledgment}

The investigators would like to thank Dr. Daigo Tanimoto, Division of Radiological diagnosis, Kawasaki Medical School, Dr. Takashi Yaguchi, Medical Mycology Research Center, Chiba University and Dr. Yoshitsugu Miyazaki, Division of Mycology, National Institute of Infectious Diseases for microbiological analysis.

\section{Author's Contributions}

Yoshihiro Kobashi: Research plan and organized the study writing of the manuscript.

Makoto Kittaka and Ryo Shirai: Help of writing of the manuscript.

Shigeki Kato: Check of the manuscript.

Mikio Oka: Final check of the manuscript.

\section{Competing Interest}

The authors declare that they have no competing interest.

\section{References}

Ambrosioni, J., D. Lew and J. Garbino,, 2010. Nocardiosis: Updated clinical review and experience at a tertiary center. Infection, 38: 89-97. DOI: $10.1007 / \mathrm{s} 15010-009-9193-9$

Backley, J.A., A.R. Padkani and J.E. Kuhlman, 1995. CT features of pulmonary nocardiosis. J. Comp. Assis. Tomogr., 19: 726-732. DOI: 10.1097/00004728-199509000-00007

Biscione, F., D. Cecchini, J. Ambrosioni, M. Bianchi and M. Corti et al., 2005. Nocardiosis in patients with human immunodeficiency virus infection. Enferm. Infect. Microbiol. Clin., 23: 419-423. DOI: $10.1157 / 13078801$

Blackmon, K.N., J.G. Ravenal, J.M. Gomez, J. Ciolino and D.W. Wray, 2011. Pulmonary nocardiosis: Computed tomography features at diagnosis. J. Thorac. Imag., 26: 224-229.

DOI: 10.1097/RTI.0b013e3181f45dd5

Brown-Elliott, B.A., J.M. Brown, P.S. Conville and R.J. Wallace, Jr, 2006. Clinical and laboratory features of the Nocardia spp. based on current molecular taxonomy. Clin. Microbiol. Rev., 19: 259-282. DOI: 10.1128/CMR.19.2.259-282.2006

Brown-Elliott, B.A., J. Biehle, P.S. Conville, S. Cohen and M. Saubolle et al., 2012. Sulfonamide resistance in isolates of Nocardia spp. from a U.S. multicenter survey. J. Clin. Microbiol., 50: 670-672. DOI: 10.1128/JCM.06243-11

Chen, Y.C., C.H. Lee, C.C. Chien, T.L. Chao and W.C. Lin et al., 2013. Pulmonary nocardiosis in southern Taiwan. J. Microbiol. Immunol. Infect., 46: 441-447. DOI: 10.1016/j.jmii.2012.07.017

Conville, P.S., B.A. Brown-Elliot, R.J. Wallace, Jr, F.G. Wiebsky and D. Koziol et al., 2012. Multisite reproducibility of the broth microdilution method for susceptibility testing of Nocardia species. J. Clin. Microbiol., 50: 1270-1280.

DOI: 10.1128/JCM.00994-11 
Feigin, D.S., 1986. Nocardiosis of the lung: Chest radiographic findings in 21 cases. Radiology, 159: 9-14. DOI: 10.1148/radiology.159.1.3952335

Garcia-Bellmunt, L., O. Sibila, I. Solanes, F. SanchezReus and V. Plaza, 2012. Pulmonary nocardiosis in patients with COPD: Characteristics and prognostic factors. Arch. Broncopneumol., 48: 280-285. DOI: $10.1016 /$ j.arbr.2012.06.006

Hui, C.H., V.W. Au, K. Rowland, J.P. Slavotinek and D.L. Gordon, 2003. Pulmonary nocardiosis re-visited: Experience of 35 patients at diagnosis. Respir. Med., 97: 709-717. DOI: $10.1053 /$ rmed.2003.1505

Husain, S., K. McCurry, J. Dauber, N. Siagh, and S. Kusne, 2002. Nocardia infection in lung transplant recipients. J. Heat Lung Transplant., 21: 354-359. DOI: 10.1016/S1053-2498(01)00394-1

Kurihara, Y., K. Tachibana, K. Tsuyuguchi, M. Akira and K. Suzuki et al., 2014. Pulmonary nocardiosis: A clinical analysis of 59 cases. Respiratory Invest., 52: 160-166. DOI: 10.1016/j.resinv.2013.09.004

Lederman, E.R. and N.F. Crum, 2004. A case series and focused review of nocardiosis: Clinical and microbiologic aspects. Medicine, 83: 300-313. DOI: 10.1097/01.md.0000141100.30871.39

Lerner, P.I., 1996. Nocardiosis. Clin. Infect. Dis., 22: 891-903. DOI: 10.1093/clinids/22.6.891

Lerner, P.I., 1995. Nocardia Species. In: Principles and Practice of Infectious Diseases, Mandell, G.L. (Eds.), Chuchill Livingstone, New York, pp: 2273-2280.

Liu, W.L., C.C. Lai, W.C. Ko, Y.H. Chen and H.J. Tang et al., 2011. Clinical and microbiological characteristics of infections caused by various Nocardia species in Taiwan: A multicenter study from 1998 to 2010. Eur. J. Clin. Microbiol. Infect. Dis., 30: 1141-1147. DOI: 10.1007/s10096-011-1227-9

Martinez Tomas, R., R.M. Villanuera, S.R. Calzada, M.S. Durantez and J.M.V. Tarazone et al., 2007. Pulmonary nocardiosis: Risk factors and outcomes. Respirology, 12: 394-400. DOI: $10.1111 / \mathrm{j} .1440-1843.2007 .01078 . \mathrm{x}$

Menendez, R., P.J. Cordero, M. Santos, M. Goberbado and V. Marco, 1997. Pulmonary infection with Nocardia species: A report of 10 cases and review. Eur. Respir. J, 10: 1542-1546.

DOI: $10.1183 / 09031936.97 .10071542$
McNeil, M.M., J.M. Brown, L.C. Hutwagner and T.A. Schiff, 1995. Evaluation of therapy for Nocardia asteroides complex infections. Infect. Dis. Clin. Pract., 4: 287-292.

DOI: $10.1097 / 00019048-199507000-00011$

NCCLS, 2003. Susceptibility testing of mycobacteria, nocardia and other aerobic actinomycetes. Approved Standard NCCLS Document M24-A.

Presant, C.A., P.H. Wiemik and A.A. Serpick, 1973. Factors affecting survival in nocardiosis. Am. Rev. Respir. Dis., 108: 1444-1448.

DOI: 10.1164 /arrd.1973.108.6.1444

Saubolle, M.A. and D. Sussland, 2003. Nocardiosis: Review of clinical and laboratory experience. J. Clin. Microbiol., 41: 4497-4501. DOI: 10.1128/JCM.41.10.4497-4501.2003

Sorrell, T.C., D.H. Mitchell and J.R. Iredell, 2005. Nocardia Species. In: Principles and Practice of Infectious Diseases, Mandell, G.L., J.E. Bennet and R. Dolon (Eds.), Churchill Livingstone, USA, pp: 2916-2924.

Uhde, K.B., S. Pathan, I. McCullium, Jr., D.P. JannatKhah and S.V. Shadomy et al., 2010. Antimicrobialresistant nocardia isolates, United States, 1995-2004. Clin. Infect. Dis., 51: 1445-1448. DOI: $10.1086 / 657399$

Valenzuela-Tovar, J.F., C. Contreras-Perez, H. ShibayamaHernandez, L. Chavez-Gonzalez and C.A. VazquezChacon et al., 2005. Biochemical identification and molecular characterization (PCR-RFLP) of Nocardia isolates from sputum. Arch. Med. Res., 36: 355-361. DOI: 10.1016/j.arcmed.2005.03.031

Wallace, Jr, R.J., M. Tsukamura, B.A. Brown, J. Brown and V.A. Steingrube et al., 1990. Cefotaximeresistant Nocardia asteroids strains are isolates of the controversial species Nocardia farcinica. J. Clin. Microbiol., 28: 2726-2732. PMID: 2280003

Wilson, J.W., 2012. Nocardiosis: Updates and clinical overview. Mayo Clin. Proc, 87: 403-407. DOI: 10.1016/j.mayocp.2011.11.016

Yorke, R.F., 2003. Nocardiosis with brain abscess due to an unusual species, Nocardia transvalensis. Arch. Pathol. Lab. Med, 127: 224-226.

DOI:

$10.1043 / 0003-$ 9985(2003)127<224:NWBADT $>2.0 . \mathrm{CO} ; 2$ 